УДК $323 ; 327 ; 328$

\title{
E.В. Ананьева
}

\section{ДИСКУРС О РОССИИ В БОРЬБЕ БРЕКЗИТЕРОВ И БРЕМЕЙНЕРОВ В БРИТАНИИ}

Референдум 2016 г. не принес решающего перевеса ни сторонникам, ни противникам членства Британии в Европейском союзе, что привело к острому их противостоянию и длительному политическому кризису в Соединенном Королевстве. Сторонники членства Британии в ЕС, а впоследствии «мягкого» брекзита, еще на этапе агитационной компании и особенно после референдума обвиняли сторонников выхода из ЕС в связях с Россией, а Россию во вмешательстве в референдум. Были проведены расследования парламентскими комитетами с целью дискредитировать брекзитеров, поставить под вопрос результаты референдума и мандат правительства на ведение переговоров с Брюсселем о выходе Британии из организации европейской интеграции. Борьба соперничающих сил прошла сквозь линии межпартийного размежевания, а ее способы выходили за рамки традиций и неписаных правил, принятых в политической культуре Соединенного Королевства. Перипетии меж- и внутрипартийной борьбы вокруг доклада «Россия» парламентского комитета по разведке и обороне показали, что правительство опасалось воздействия доклада на избирателей в преддверие досрочных всеобщих выборов 2019 г. Расследование не выявило доказательств вмешательства России в референдум, как и в референдум 2014 г. о независимости Шотландии, а также в парламентские выборы 2017 и 2019 гг. Тем не менее доклад стал поводом для взаимных обвинений сторон в предвыборной кампании 2019 г. Установка Лондона на концепцию «Глобальной Британии» свидетельствует о том, что Соединенное Королевство, независимо от исхода переговоров с ЕС, рассматривает Москву как стратегического противника.

Ключевые слова: Великобритания, брекзит, ЕС, США, Россия, Борис Джонсон, выборы, референдум, Шотландия.

DOI: $10.35634 / 2587-9030-2020-4-4-438-444$

\section{Введение}

Референдум о членстве Британии в Европейском союзе 2016 г. привел к расколу в обществе и в правящем классе, поскольку разрыв оказался в пределах статистической погрешности (52\%: 48 \%). Брекзит, важнейший внешнеполитический и внутриполитический вопрос для Соединенного Королевства, вызвал ожесточенную меж- и внутрипартийную борьбу как накануне референдума 2016 г., так и после него. В попытке предотвратить или ускорить «развод» с Брюсселем стороны - и брекзитеры (сторонники выхода из ЕС) и бремейнеры (сторонники членства Британии в ЕС) - использовали любые приемы. Брекзит стал причиной острого политического кризиса, вылившегося в противостояние исполнительной, законодательной и судебной ветвей власти, смене трех премьер-министров и трех выборов за 4 года. Отношения Британии и России ко времени референдума уже были во многих сферах свернуты и после него еще больше осложнились, став заложником брекзита. В статье дан анализ методов, которые применяли брекзитеры и бремейнеры, чтобы ослабить друг друга, принося двусторонние отношения с Россией в жертву своим политическим интересам.

Со времени агитационной кампании в преддверии референдума о членстве Британии в ЕС и до настоящего времени обе стороны обвиняют друг друга в связях с Россией, хотя претензии не ограничиваются лишь полемикой вокруг брекзита.

Поскольку премьер-министр Д. Кэмерон поддерживал членство страны в ЕС, то он и министр иностранных дел Ф. Хэммонд, уговаривая британцев голосовать на референдуме за членство страны в ЕС, называли Россию одним из главных бенефициаров брекзита ${ }^{1}$. Создавалось впечатление, будто референдум затеяла «коварная» Россия. Между тем Москва не высказывала своих оценок и никоим образом не пыталась воздействовать на общественное мнение в Соединенном Королевстве. Самих британцев, как показывали опросы, накануне референдума больше всего беспокоила не «российская угроза», а иммиграция из стран ЕС [9].

Всплеск в Британии в январе 2016 г. антироссийской риторики (публикация доклада по «делу Литвиненко», два фильма Би-би-си о «богатстве» В. Путина и вероятном сценарии начала третьей мировой войны) были неслучайными: Лондон использовал его как рычаг давления при переговорах с

\footnotetext{
${ }^{1}$ Ф. Хэммонд признался после референдума, что лишь «строил предположения» относительно логики Москвы.
} Цит. по: URL: https://regnum.ru/news/polit/2154513.html (дата обращения: 10.10.2020). 
ЕС, накануне обнародования стратегии НАТО в Европе в конце января, а после переговоров с ЕС уже непосредственно для влияния на исход референдума [4].

Как ни запугивали «российской угрозой» премьер-министр и министр иностранных дел, британцы этим страхам не поддались. В России приняли результаты референдума, хотя Президент В. Путин отметил, что «...сама организация этого референдума и ... результаты не что иное, как самоуверенность и поверхностное отношение к решению судьбоносных вопросов для своей собственной страны, да и для Европы в целом со стороны руководства Великобритании... Это выбор подданных Великобритании. Мы никак в это не вмешивались, не вмешиваемся и вмешиваться не собираемся» [3].

После референдума СМИ, выступавшие на стороне бремейнеров, опубликовали материалы о злоупотреблениях агитационных кампаний брекзитеров Vote Leave (которую возглавляли Б. Джонсон и М. Гоув) и Leave.EU (которую возглавлял и спонсировал Аарон Бэнкс). В ноябре 2017 г. первые полосы газет и новостные каналы переполняли журналистские «расследования» о вмешательстве России в референдум 2016 г. на стороне брекзитеров ${ }^{2}$.

С 2017 г. парламентский Комитет по цифровому развитию, культуре, СМИ и спорту (председатель комитета, консерватор Д. Коллинз, до референдума выступал против брекзита) вел расследование [5] в отношении вмешательства России в выборы 2017 г. и в референдум, а также кампаний брекзитеров. Расследованиями занимались Избирательная комиссия, Бюро по информации (Information Commissioners Office). Национальное агентство по противодействию преступности (National Crime Agency) вело расследование лично против предпринимателя Аарона Бэнкса, который встречался с сотрудниками посольства РФ в Британии и имел тесные связи с Н. Фараджем, лидером Партии независимости Соединенного Королевства (ПНСК), и Д. Трампом, кандидатом в президенты США.

Обе кампании брекзитеров были оштрафованы за злоупотребления в агитации, но в ходе расследования, которое длилось два года, связей Бэнкса с «третьей стороной» не обнаружили, как и состава преступления [11].

Бюро по информации, начав расследование в 2017 г., в октябре 2020 г. вынесло заключение [7], что оно не выявило «существенные нарушения» закона кампаниями бремейнеров и брекзитеров. Правда, в письме парламентскому Комитету глава Бюро Элизабет Денэм отметила, что, хотя «предполагаемое российское вмешательство не входило в сферу компетенции расследования, регулятор не выявил «каких-либо дополнительных свидетельств» российского вмешательства в материалах... фирмы “Кэмбридж аналитика”».

1 ноября 2017 г. Комитет Палаты общин вызвал Б. Джонсона, тогда министра иностранных дел в правительстве Терезы Мэй, на слушания по вопросу о вмешательстве России в выборы 2017 г. и референдум 2016 г. Джонсон по-русски ответил «неэт», добавив по-английски «никак» ${ }^{3}$.

Как признавала газета "The Washington Post"4, критики Т. Мэй считали, что вмешательство России ставит под вопрос мандат Консервативной партии на вывод Британии из ЕС. Премьерминистр утверждала, что российская «пропаганда» не оказала «прямого успешного воздействия»на голосование на референдуме. Обвинения в российском вмешательстве обострили разногласия в самой Консервативной партии между сторонниками «жесткого» и «мягкого» брекзита, а их вместе - с бремейнерами, считавшими брекзит исторической ошибкой.

Вместе с тем 13 ноября 2017 г. Т. Мэй обвинила Россию в том числе и в распространении фейков и кибер-шпионаже, вмешательстве в выборы, чтобы «посеять раздор на Западе»: «Мы знаем, чем вы занимаетесь, и вы не преуспеете» [10]. Ее обвинения резко контрастировали с утверждениями Д. Трампа об отсутствии вмешательства России в президентские выборы 2016 г. в США.

В свою очередь, Лейбористская партия обвиняла премьер-министра в путаных комментариях относительно вмешательства России (Мэй утверждала, что вмешательство не касалось Британии) в попытке подыграть Трампу, надеясь на «утопическое» соглашение о свободной торговле с США в условиях «катастрофы» брекзита. Лейбористы потребовали, чтобы Комитет по разведке и обороне приступил к расследованию, которое началось в тот же день.

\footnotetext{
${ }^{2}$ Mosrous A. et al. Russia used Twitter bots and trolls 'to disrupt' Brexit vote. The Times. 15.11.2017

3 Boris Johnson's 'nyet' on Russian influence in UK elections. URL: https://www.bbc.com/news/av/uk-politics41829717. 01.11.2017 (accessed: 10.10.2020)

${ }^{4}$ Adam K. Rising alarm in Britain over Russian meddling in Brexit vote. Available at: https://www.washingtonpost.com/ world/europe/rising-alarm-in-britain-over-russian-meddling-in-brexit-vote/2017/11/17/2e987a30-cb34-11e7-b506-8a10ed

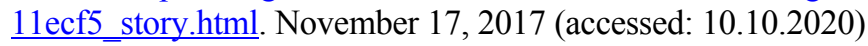


Практически весь 2018 г. прошел под знаком инцидента в Солсбери. «Дело Скрипалей» скорее было акцией внешнеполитической, связанной со стремлением Лондона в условиях сложных переговоров с Брюсселем по брекзиту оказать давление на партнеров по ЕС и более широким геополитическим контекстом [2].

\section{Доклад «Росссия»}

Вокруг доклада о вмешательстве России развернулась серьезная борьба между брекзитерами и бремейнерами.

Комитет по разведке и обороне возглавлял тори Д. Грив, бывший генеральный прокурор, активный бремейнер, призывавший провести повторный референдум по членству страны в ЕС и готовый поддержать вотум недоверия своему консервативному правительству в случае «плохой сделки» с Брюсселем, которая повлечет «катастрофический ущерб». Он также внес вклад в предотвращение приостановки работы парламента Джонсоном в сентябре 2019 г., которую Верховный суд признал «ничтожной и незаконной».

Доклад Комитета был готов в марте 2019 г., но вышел он только в июле 2020 г., поскольку вмешались внутриполитические события.

Весной 2019 г. за позицию Д. Грива по брекзиту местное отделение партии выразило ему недоверие, пригрозив не выставлять его кандидатуру на следующих парламентских выборах, неизбежность которых назрела. После ухода Т. Мэй в отставку летом 2019 г. лидером партии тори и премьерминистром стал брекзитер Б. Джонсон, который исключил Грива из партии в ряду других бунтарейзаднескамеечников, голосовавших против законопроектов его правительства. Грив оставался на посту председателя Комитета до 6 ноября 2019 г.

Досрочные выборы были назначены на 12 декабря, а за 5 недель до выборов парламент распускают, и публикация доклада была отложена. Неопубликованный доклад комитета фигурировал и в предвыборной полемике. Отвергая упреки в нежелании придать докладу гласность, Джонсон сравнил его «с мифом о Бермудском треугольнике» ${ }^{5}$. Консервативная партия одержала на выборах убедительную победу, чему способствовала мажоритарная избирательная система. Джонсон санкционировал публикацию доклада 13 декабря - на следующий день после выборов.

Как правило, между санкцией премьер-министра и выходом парламентских докладов в свет проходит 10 дней, однако Джонсон обосновал очередную задержку публикации предстоявшим формированием нового состава Комитета по разведке и обороне. Джонсону не удалось провести на пост председателя комитета своего кандидата К. Грейлинга: 15 июля 2020 г., вопреки Джонсону и при поддержке лейбористов и либерал-демократов, председателем был избран «самовыдвиженец» консерватор Дж. Льюис (прежде председатель парламентского Комитета по обороне), за что Джонсон исключил его из партии. Льюис - брекзитер и активный сторонник модернизации ядерной системы «Трайдент», выступает за рост оборонных расходов Британии до 3\% в год. Премьер-министр затягивал формирование комитета под предлогом исключения из партии (прерогатива лидера партии) члена комитета от тори ${ }^{6}$. К июню 2020 г. доклад еще не был опубликован, а комитет не собирался, что послужило основанием для межпартийной группы депутатов направить письмо премьеру с обвинениями в «противодействии демократии» ${ }^{7}$. Доклад был опубликован 21 июля 2020 г., именно перед роспуском парламента на летние каникулы, чтобы снизить его резонанс.

При составлении доклада, помимо официальных должностных лиц из МИДа, разведки, Министерства обороны и других ведомств, в качестве свидетелей были привлечены: Энн Эпплбаум, сотрудница Института глобальных проблем ${ }^{8}$, супруга бывшего маршала Сейма и министра иностран-

\footnotetext{
${ }^{5}$ Woodcock A. 'This is Bermuda Triangle stuff: Boris Johnson heckled by Question Time audience as he dodges questions on Russia report. 22.11.2020. URL: https://www.independent.co.uk/news/uk/politics/boris-johnson-russia-reportquestion-time-election-debate-audience-a9214556.html (accessed: 10.10.2020)

6 Здесь речь идет уже об условиях соглашения о свободной торговле, которое правительство Джонсона стремится заключить с Вашингтоном. Депутаты опасаются, что оно будет невыгодным для Британии и снизит стандарты продукции, против чего и голосовал депутат-тори (см. ниже).

${ }^{7}$ Busby M. Russia report: UK MPs condemn 'utterly reprehensible' delay. URL: https://www.theguardian.com/ politics/2020/jun/20/russia-report-uk-mps-condemn-utterly-reprehensible-delay. 20.06.2020 (accessed 10.10.2020).

${ }^{8}$ Институт создан при Лондонской школе экономики. Э. Эпплбаум специализируется на «демократизации» СССР и стран Восточной Европы, руководит программой «Арена» по изучению современных методов дезин-
} 
ных дел Р. Сикорского (оба работали в American Enterprise Institute - крайне правом «мозговом центре» США, выступали за продвижение НАТО на восток); Эдвард Лукас, бывший шеф московского бюро журнала "The Economist", а ныне обозреватель газеты "The Times"; Кристофер Стил, один из авторов доклада о связях Трампа с Россией ${ }^{9}$, составленного по заказу Демократической партии США к президентским выборам 2016 г. Стил имел отношение еще и к «делу Скрипалей» ${ }^{10}$. Среди внешних экспертов был и Билл Браудер, который обвиняется в неуплате налогов в России и инициировал «Акт Магницкого» в США ${ }^{11}$; Кристофер Доннелли, директор «Института государственного правления» (Institute for Statecraft), финансируемого правительством и участвующего в полугосударственном проекте Integrity Initiative ${ }^{12}$ для информационного противодействия России (получается, что государство запрашивало у своих платных пропагандистов мнение о российских пропагандистах). Все эти внешние эксперты известны крайне правыми и антироссийскими взглядами. Ни один эксперт по России из академических и дипломатических кругов привлечен не был, как и ни один гражданин России. Таким образом, доклад заранее не был сбалансирован.

В представленном документе [8] очень много «звездочек», прикрывающих секретные сведения, которые будут доступны лишь узкому кругу высокопоставленных должностных лиц. Соответственно, многие эксперты и написали, что он «пустой».

Россию обвинили во вмешательстве во все значимые политические события Британии: референдум о независимости Шотландии (хотя в 2014 г. подобных обвинений не было), референдум о членстве Британии в ЕС (2016 г.), выборы 2017 и 2019 гг. Безусловно, все эти события имеют отношение к брекзиту. Шотландия ныне добивается повторного референдума о независимости в силу «изменившихся обстоятельств» из-за брекзита, против которого проголосовал регион. Основным темой парламентских выборов 2017 г. и 2019 г. также был брекзит.

В докладе содержится констатация, что российские издания "Sputnik" и "Russia Today" публиковали материалы якобы в пользу выхода Британии из ЕС. Однако вся пресса, которая принадлежит Р. Мёрдоку ${ }^{13}$, годами публиковала такие материалы. Сам Б. Джонсон, будучи еще корреспондентом газеты "The Telegraph" в Брюсселе, также писал статьи против ЕС. Напомним, что Уинстон Черчиль в своей «Цюрихской речи» в сентябре 1946 г. говорил о «Соединенных Штатах Европы»: после разрушительных войн, которые на европейском континенте развязывали либо Франция, либо Германия, нужно тесно переплести их экономики, чтобы они больше не начинали войну, для чего и нужна интеграция. Черчилль отводил роль благосклонных наблюдателей Соединенному Королевству, США и СССР, т. е. изначально не предполагалось, что сама Британия будет участвовать в процессе европейской интеграции.

Примечательна заочная полемика Джонсона и В. Путина в июне 2019 г. по поводу утверждения российского президента о кризисе современной либеральной идеи [12;6]. По мнению в то время кандидата на пост британского премьера, Соединенное Королевство продемонстрирует «ценность либерализма», выйдя из Евросоюза, а отказ страны от брекзита или новый референдум сделают демокра-

формации и пропаганды, создает «Лабораторию трансформации» - программу по политической и экономической трансформации отдельных стран.

9 Досье на Д. Трампа было составлено на слухах, собранных политологом Игорем Данченко, бывшим сотрудником Института Брукингса в Вашингтоне. Barrett D. et al. Justice Dept. disclosures cast fresh doubt on TrumpRussia investigation. 26.09.2020. URL: https://www.washingtonpost.com/national-security/new-justice-dept-disclosurescast-fresh-doubt-on-trump-russia-investigation/2020/09/25/f08ccfb0-ff61-11ea-9ceb-061d646d9c67_story.html (accessed: 10.10.2020).

${ }^{10}$ Куратор С. Скрипаля, агент МИ-6 Пабло Миллер, работал на фирму “Orbis Business Intelligence” К. Стила, сотрудника МИ-6, работавшего в британском посольстве в Москве при вербовке С. Скрипаля.

11 Дело № 32631/09 и 53799/12 «Магнитский и другие против России». URL: http://european-court-help.ru/delo32631-09-i-53799-12-magnitskii-i-drugie-prot/ (дата обращения: 10.10.2020)

12 B Anonymous рассказали о финансировании проектов "Институт госуправления". 11.02.2019. URL: https://ria.ru/20190211/1550701555.html (accessed: 10.10.2020). См. также подборку материалов РИА Новости: URL: https://ria.ru/integrity_initiative_scandal/ (дата обращения: 10.10.2020); сайт Integrity Initiative: https://integrityinitiative.com/; Те еще тролли. Кому Британия платит за «противодействие России». 24.11.2018. URL: https://ria.ru/20181124/1533430472.html (дата обращения: 10.10.2020).

${ }^{13}$ Руперп Мёрдок - медиамагнат, владелец СМИ, издательств, кинокомпаний в США, Европе, Австралии, Азии, Латинской Америке, основатель News Corp и 21st Century Fox. 
тию «посмешищем». Таким образом, брекзит должен состояться, по мнению Джонсона, уже не в интересах России, а «вопреки» России.

Не удивительны и заявления доклада, что Россия якобы вмешивалась в выборы 2019 г. Перед этими выборами лидер оппозиционной Лейбористской партии Дж. Корбин представил материалы о переговорах Лондона и Вашингтона по торговому соглашению, которое предполагается заключить после выхода Британии из ЕС. Материалы касались того, что Лондон готов позволить американским компаниям частично приватизировать Национальную службу здравоохранения, а также о продлении патентного права американских фармацевтических компаний на лекарства, что означает их подорожание для британцев. Корбина обвинили в том, что он взял эти сведения из российских источников в целях предвыборной борьбы.

В докладе рассматривался вопрос и о связях тори с «русскими олигархами», которые вносили средства в казну Консервативной партии, имели доступ к высшим кругам общества и отмывали деньги в Лондоне. Намек был очевидным: правительства консерваторов от Кэмерона до Джонсона закрывают глаза на российское вмешательство из-за связей с «русскими олигархами» ${ }^{14}$.

Эти неблагоприятные новости для правительства Джонсона имели бы значение перед выборами. Именно по этой причине правительство не желало выпускать доклад до выборов 2019 г.

В докладе сделан вывод: Россия не смогла повлиять на демократические процедуры королевства. Авторам доклада нужно определиться с той позицией: либо в Британии живут сознательные граждане, которые столетиями учились голосовать осознанно, либо жалкие обыватели, которых можно качнуть в любую сторону в любой момент.

22 июля в парламенте премьер-министр по понятным причинам отметил, что доклад не содержит никаких доказательств того, что Россия влияла на референдум 2016 г.: критика и обвинения правительства в нежелании расследовать «российское вмешательство» в референдум - происки бремейнеров, их гнев и ярость, что в докладе нет убедительных доказательств. Джонсон отказался начать отдельное расследование о российском вмешательстве в референдум 2016 г.

Характерно, что, упреждая публикацию доклада, глава Форин-офис Д. Рааб в министерском заявлении отметил, что Россия «почти наверняка» пыталась повлиять на итоги декабрьских выборов 2019 г., «активно распространяя незаконно полученные и ставшие доступными в результате утечки правительственные документы». Правительство тем самым единственный раз признало обоснованность положения доклада, поскольку касалось оно оппозиционной Лейбористской партии (имелись в виду полученные якобы из российских источников материалы, которые обнародовал Дж. Корбин о переговорах Лондона и Вашингтона) $)^{15}$. Одно отдельное расследование - о том, как конфиденциальные материалы о переговорах попали в открытый доступ через платформу Reddit, - правительство открыло.

МИД России и пресс-секретарь Президента РФ отреагировали на доклад следующей оценкой: бездоказательная «русофобия в фейковой огранке» ${ }^{16}$.

Публикация другого документа, Обзора стратегии национальной безопасности и обороны, который готовит правительство Б. Джонсона, также откладывается, но уже по причинам ожидания исхода переговоров с ЕС и президентских выборов в США.

\section{Заключение}

Перипетии внутриполитической борьбы вокруг брекзита показывают, что она идет сквозь линии межпартийного размежевания. Бремейнеры инициировали против брекзитеров расследования, которые по существу «родили мышь». Однако Британия расценивает Россию как стратегического противника. При любом политическом раскладе национальные интересы двух стран не совпадают. Установка Лондона на концепцию «Глобальной Британии» свидетельствует о том, что Соединенное Королевство выстраивает с Северной Европой, Польшей, Украиной модель противодействия России у ее границ. Другой вопрос, что у Британии нет вечных друзей и врагов, а есть лишь постоянные интересы.

\footnotetext{
14 Обладая британскими паспортами, выходцы из России имеют право регистрироваться в качестве избирателей, а избиратели вправе направлять пожертвования политическим партиям. Сведения о пожертвованиях партиям регулярно публикует Избирательная комиссия.

${ }^{15}$ Kuenssberg L. 'Almost certain' Russians sought to interfere in 2019 UK election - Raab. URL: https://www.bbc.com/ news/uk-politics-53433523. 16.07.2020 (accessed: 10.10.2020).

16 Захарова назвала британский доклад «русофобией в фейковой огранке». URL: https://tass.ru/politika/9015415 (дата обращения: 10.10.2020).
} 
Неопределенность ситуации и смещение баланса сил внутри ЕС могут негативно сказаться на России. Станет ли Германия безраздельно доминировать в ЕС? Последует ли за брекзитом неизбежное обострение противоречий в Европе в непосредственной близости от российских границ? Подобные вопросы представляют для России отнюдь не академический интерес. Так что «заинтересованность» России в брекзите скорее блеф тех, кто был готов на любые средства ради оправдания цели.

\section{СПИСОК ЛИТЕРАТУРЫ:}

1. Ананьева Е.В. Брекзит: голосовали сердцем // «Международная жизнь». 2016. № 7. С. 47-61.

2. Ананьева Е., Годованюк К. Матрешка «дела Скрипалей» // Современная Европа. 2018. № 3. С. $16-27$.

3. Путин В. Ответы на вопросы журналистов. URL: http://www.kremlin.ru/events/president/transcripts/52264 (дата обращения: 10.10.2020).

4. Cameron D. David Cameron: Brexit would be "gamble of the century". URL: http://www.telegraph.co.uk/news/ politics/david-cameron/12176325/David-Cameron-Brexit-would-be-gamble-of-the-century.html 27/02/2016 (accessed: 12.10.2020).

5. Digital, Culture, Media and Sport Committee. Disinformation and 'fake news': Interim Report. House of Commons. Fifth Report of Session 2017-2019. Published 24 July 2018. URL: https://publications.parliament.uk/pa/ cm201719/cmselect/cmcumeds/363/363.pdf (accessed 10.10.2020)

6. Johnson B. "We Will Prove Vladimir Putin Wrong by Leaving the EU by October 31". 30.06.2019. URL: http://www.telegraph.co.uk/politics/2019/06/30/will-prove-vladimir-putin-wrong-leaving-eu-october-31/ (accessed: 10.10.2020).

7. Information Commissioners Office. URL: https://ico.org.uk/media/action-weve-taken/2618383/20201002_ico-o-ed1-rtl-0181_to-julian-knight-mp.pdf (accessed: 02.10.2020).

8. Intelligence and Security Committee of Parliament. 21 July 2020. Russia. URL: https://docs.google.com/a/ independent.gov.uk/viewer?a=v\&pid=sites\&srcid=aW5kZXBlbmRlbnQuZ292LnVrfGlzY3xneDo1Y2RhMGEyN2Y3NjM 0OWFl (accessed: 09.10.2020).

9. Ipsos-MORI. The Perils of Perception and the EU. URL: https:/www.ipsos-mori.com/researchpublications/ researcharchive/3742/The-Perils-of-Perception-and-the-EU.aspx. 09.06.2016 (accessed: 10.10.2020).

10. May Th. PM speech to the Lord Mayor's Banquet 2017. Available at: https://www.gov.uk/government/speeches/pmspeech-to-the-lord-mayors-banquet-2017 (accessed: 10.10.2020).

11. National Crime Agency. "Public statement on NCA investigation into suspected EU referendum offences". 24 September 2019. URL: https://nationalcrimeagency.gov.uk/news/public-statement-on-nca-investigation-into-suspectedeu-referendum-offences (accessed: 10.10.2020).

12. Putin, Vladimir. 2019. Transcript: 'All this fuss about spies ... it is not worth serious interstate relations'. The Financial Times. 27.06.2019. URL: http://www.ft.com/content/878d2344-98f0-11e9-9573-ee5cbb98ed36 (accessed: 10.10.2020).

Поступила в редакцию 17.10.2020

Ананьева Елена Владимировна, кандидат философских наук, ведущий научный сотрудник, руководитель Центра британских исследований Институт Европы РАН 125009, Россия, г. Москва, ул. Моховая, 11, стр. 3

E-mail: e-ananieva@yandex.ru.

\section{E.V. Ananieva}

\section{RUSSIA IN THE DISCOURSE OF BREXETEERS AND BREMAINERS IN THE UK}

DOI: $10.35634 / 2587-9030-2020-4-4-438-444$

The UK EU membership referendum (2016) brought a confused result not giving the Brexiteers or the Bremainers decisive preponderance. This led to sharp divisions in the society at large, and a prolonged political crisis in Britain. Bremainers as early as at the stage of the pre-referendum campaign accused Brexiteers of being under the influence of Russia, meddling on the part of Brexit. The Bremainers initiated a series of inquiries into Russian interference to discredit the Brexiteers, putting under question the results of the referendum and the mandate of the UK government to conduct negotiations with Brussels. This confrontation went through lines of interparty divisions, and its methods went beyond the traditions and unwritten rules of the United Kingdom's political culture. The vicissitudes of inter- and intra- 
party infighting around the Parliamentary Intelligence and Defence Committee's report "Russia" showed that the government feared the report would influence voters in the run-up to the 2019 early general election. The investigation found no evidence of Russian interference in the referendum, nor in the 2014 Scottish independence referendum or the 2017 and 2019 parliamentary elections. Nevertheless, the "Russia" report became the basis for mutual accusations of the parties in the 2019 election campaign. London's focus on the concept of "Global Britain" indicates that the United Kingdom, regardless of the outcome of negotiations with the EU, views Russia as a strategic adversary.

Keywords: Brexit, Boris Johnson, UK parliament, EU, USA, Russia, Brexiteers, Bremainers, elections, referendum, Scotland.

Ananieva E.V., Candidate of Philosophy, Head of Centre for UK Studies Institute of Europe, Russian Academy of Sciences

Mokhovaya st., 11/3, Moscow, Russia, 125009

E-mail: e-ananieva@yandex.ru 